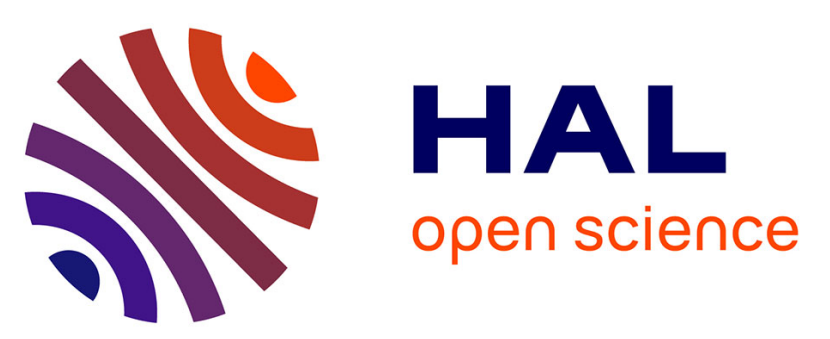

\title{
Electrical conductivity improvement of aeronautical carbon fiber reinforced polyepoxy composites by insertion of carbon nanotubes
}

Antoine Lonjon, Philippe Demont, Eric Dantras, Colette Lacabanne

\section{To cite this version:}

Antoine Lonjon, Philippe Demont, Eric Dantras, Colette Lacabanne. Electrical conductivity improvement of aeronautical carbon fiber reinforced polyepoxy composites by insertion of carbon nanotubes. Journal of Non-Crystalline Solids, 2012, pp. 358, pp. 1859-1862. 10.1016/j.jnoncrysol.2012.05.038 . hal-00837753

\section{HAL Id: hal-00837753 \\ https://hal.science/hal-00837753}

Submitted on 24 Jun 2013

HAL is a multi-disciplinary open access archive for the deposit and dissemination of scientific research documents, whether they are published or not. The documents may come from teaching and research institutions in France or abroad, or from public or private research centers.
L'archive ouverte pluridisciplinaire HAL, est destinée au dépôt et à la diffusion de documents scientifiques de niveau recherche, publiés ou non, émanant des établissements d'enseignement et de recherche français ou étrangers, des laboratoires publics ou privés. 


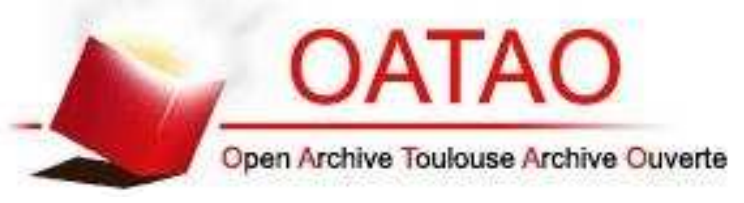

Open Archive Toulouse Archive Ouverte (OATAO)

OATAO is an open access repository that collects the work of Toulouse researchers and makes it freely available over the web where possible.

This is an author-deposited version published in: http://oatao.univ-toulouse.fr/ Eprints ID: 8734

To link to this article: DOI: $10.1016 / j$.jnoncrysol.2012.05.038

Official URL: http://dx.doi.org/10.1016/j.jnoncrysol.2012.05.038

\section{To cite this version:}

Lonjon, Antoine and Demont, Philippe and Dantras, Eric and Lacabanne, Colette Electrical conductivity improvement of aeronautical carbon fiber reinforced polyepoxy composites by insertion of carbon nanotubes. (2012) Journal of Non-Crystalline Solids, pp. 358 (vol. 15). pp. 1859-1862. ISSN 00223093

Any correspondence concerning this service should be sent to the repository administrator: staff-oatao@inp-toulouse.fr 


\title{
Electrical conductivity improvement of aeronautical carbon fiber reinforced polyepoxy composites by insertion of carbon nanotubes
}

\author{
Antoine Lonjon *, Philippe Demont, Eric Dantras, Colette Lacabanne \\ Physique des Polymères, CIRIMAT/Institut Carnot, Université Paul Sabatier, 118 route de Narbonne, 31062 Toulouse cedex 9, France
}

Keywords:

Composites;

Carbone nanotubes;

Conductivity

\begin{abstract}
A B S T R A C T
An increase and homogenization of electrical conductivity is essential in epoxy carbon fiber laminar aeronautical composites. Dynamic conductivity measurements have shown a very poor transversal conductivity. Double wall carbon nanotubes have been introduced into the epoxy matrix to increase the electrical conductivity. The conductivity and the degree of dispersion of carbon nanotubes in epoxy matrix were evaluated. The epoxy matrix was filled with $0.4 \mathrm{wt} . \%$ of CNTs to establish the percolation threshold. A very low value of carbon nanotubes is crucial to maintain the mechanical properties and avoid an overload of the composite weight. The final carbon fiber aeronautical composite realized with the carbon nanotubes epoxy filled was studied. The conductivity measurements have shown a large increase of the transversal electrical conductivity. The percolative network has been established and scanning electron microscopy images confirm the presence of the carbon nanotube conductive pathway in the carbon fiber ply. The transversal bulk conductivity has been homogenized and improved to $10^{-1} \mathrm{~S} \cdot \mathrm{m}^{-1}$ for a carbon nanotubes loading near $0.12 \mathrm{wt} . \%$.
\end{abstract}

\section{Introduction}

Nowadays composite materials are increasingly used by aeronautical companies to reduce the aircrafts weight. In spite of the electrical conductivity of carbon fibers, composites have a poor isotropic conductivity [1]. This low conductivity made composite structures more vulnerable to withstand to lightning strikes and unable to prevent electrostatic accumulation. Carbon fiber/epoxy laminates composites are heterogeneous materials and physical properties such as electrical conductivity depend on carbon fiber ply orientation.

Generally an epoxy/carbon fiber composite is comprised of $57 \%$ in vol. of carbon fibers. In the case of epoxy system for Resin Transfer Moulding (RTM) composites, this high volume fraction of fibers allows a conductivity of $10^{-1} \mathrm{~S} \cdot \mathrm{m}^{-1}$ in transverse laminates. This value is close to the conductivity of an epoxy matrix loaded with carbon (black or short fibers) [2-5] above the percolation threshold. The new generations of aeronautical composites are made with layers of pre-impregnated carbon fiber with epoxy resin on both sides [6]. These pre-impregnated layers are then assembled together and cured in autoclave. The studied example is an assembly of unidirectional (UD) prepreg. The conductivity of composite structure is a function of the fiber orientation. The thickness of the inter-laminar epoxy layer could be enough to electrically insulate the successive carbon fiber layer. It is therefore necessary to increase the electrical conductivity of the epoxy matrix to improve the transversal conductivity across the composite section.

\footnotetext{
* Corresponding author.

E-mail address: antoine.lonjon@univ-tlse3.fr (A. Lonjon).
}

Carbon nanotubes are particles with a high aspect ratio [7] $(\xi \sim 1000)$. Carbon nanotubes provide the level of conductivity [8] of an epoxy resin filled with carbon black [4]. Due to their high aspect ratio, this value is obtained for a very low weight fraction $(<0.5$ wt.\%) [9-13]. This very low rate allows us to maintain the mechanical properties of epoxy matrix for a relatively small weight gain [14]. A previous study has reported the elaboration of a hybrid composite architecture of CNTs directly synthesized on a cloth of alumina fibers [15]. The final composite loading of CNTs corresponds to 1 to 3 vol.\% and permits conductivity across thickness direction near $10^{-4} \mathrm{~S} \cdot \mathrm{m}^{-1}$. This value indicates a CNT bridging of the insulating epoxy interlaminar region between plies. Similar results were observed with glass fiber composites and CNTs dispersed in the matrix [14] or with Carbon nanofibers [16] as conductive filler. In the case of carbon fiber composites, interlaminar mechanical reinforcement using aligned CNTs was studied [17]; an electrical property improvement of $30 \%$ was demonstrated in the case of carbon fibers covered with carbon nanotubes by electrophoresis [18].

The aim of this study is to introduce carbon nanotubes in the epoxy matrix of the prepreg to homogenize the bulk volume conductivity of composites structure.

\section{Experimental section}

\subsection{Materials and sample preparation}

The composite was T700GC/M21 and supplied by Hexcel composites and the carbon fibers have an electrical conductivity around $10^{4}$ $10^{5} \mathrm{~S} \cdot \mathrm{m}^{-1}[19]$. Double wall carbon nanotubes (DWCNTs) elaborated 
by CVD [20] were supplied by Marion technologies with an intrinsic electrical conductivity of one CNT around $10^{5}-10^{6} \mathrm{~S} \cdot \mathrm{m}^{-1}$ [21]. The palmitic acid was supplied by Sigma Aldrich. The M21 resin is a multicomponent epoxy system. M21 epoxy resin was directly supplied by Hexcel composite with separated components. CNTs were dispersed in M21 in two steps. A previous work [22] on CNT dispersion in epoxy has shown a percolation threshold near $0.3 \mathrm{wt} . \%$ with palmitic acid as amphiphilic molecule. In this study, a CNT weight fraction of $0.4 \% \mathrm{wt}$ was chosen. The CNTs were dispersed in acetone with palmitic acid (1:1 by weight). The epoxy component of M21 was also dissolved in acetone. The dispersed CNTs were then poured into the polymer solution, and the mixture was submitted to a short sonication pulse for $3 \mathrm{~min}$, corresponding to a dissipated power of $300 \mathrm{~W}$. A suitable dispersion of the CNTs in the polymer solution was obtained. The solvent was evaporated using a magnetic stirrer at $80^{\circ} \mathrm{C}$ for $1 \mathrm{~h}$. The epoxy component filled with CNTs was poured into the other M21 components. The M21 filled with CNTs was used to elaborate M21 nanocomposites and M21 prepregs for carbon fiber (CF) composites. All the prepregs unfilled and filled with CNTs were made with the same technique and by the same person in Hexcel Composites. Composites made with and without CNTs have been identically prepared. The curing process took place for 120 min at $180^{\circ} \mathrm{C}$ with a pressure of 7 bars. For CF composites, 8 prepregs were assembled with UD carbon fiber oriented in the same direction $\left[0^{\circ}\right]$.

\subsection{Electrical conductivity}

Electrical conductivity measurements were carried out by recording the complex conductivity $\sigma^{*}(\omega)$ using a Novocontrol broadband spectrometer [23]. The measurements were carried out between $10^{-2}$ and $10^{6} \mathrm{~Hz}$ at room temperature. The real part $\sigma^{\prime}(\omega)$, of the complex conductivity was investigated. The value of conductivity $\sigma_{\mathrm{dc}}$ is obtained by the low frequency limit of $\sigma^{\prime}(\omega)$ at $10^{-2} \mathrm{~Hz}$. A sample $2 \mathrm{~mm}$ in thickness was placed between two circular gold plated electrodes $(20 \mathrm{~mm}$ in diameter). To reduce contact resistance with the cell electrodes, the samples are silver coated onto both sides using conductive silver paint.

\subsection{Electron microscopy}

The morphology of nanocomposites and composites was observed by scanning electron microscopy (SEM) using a JEOL JSM 6700F equipped with a field emission gun (SEM-FEG). Nanocomposite and composites samples were cryo-fractured at the liquid nitrogen temperature.

\section{Results}

\subsection{Composite morphology}

The M21 UD carbon fiber composite was cryo-cut. The transverse fracture was observed by scanning electronic microscopy. The SEM image reported in Fig. 1 shows three interleaf of M21 (B) between four prepreg carbon fiber layers (A). The thickness of each CF prepreg is about $200 \mu \mathrm{m}$ and about $35 \mu \mathrm{m}$ for the M21 interlayer. This observation explains the poor transversal conductivity ( $z$ direction) of carbon fiber M21 composites. The total conductivity was due to the resistance of the interlayer rich in polymer. This result confirms the interest of increasing the polymer conductivity with carbon nanotubes.

\subsection{Electrical behavior}

The conductivity of M21 was measured and used as the polyepoxy reference. M21 filled with CNTs were elaborated and its conductivity measured. Carbon fiber composite with M21 filled with CNTs was assembled and its electrical behavior was determined.

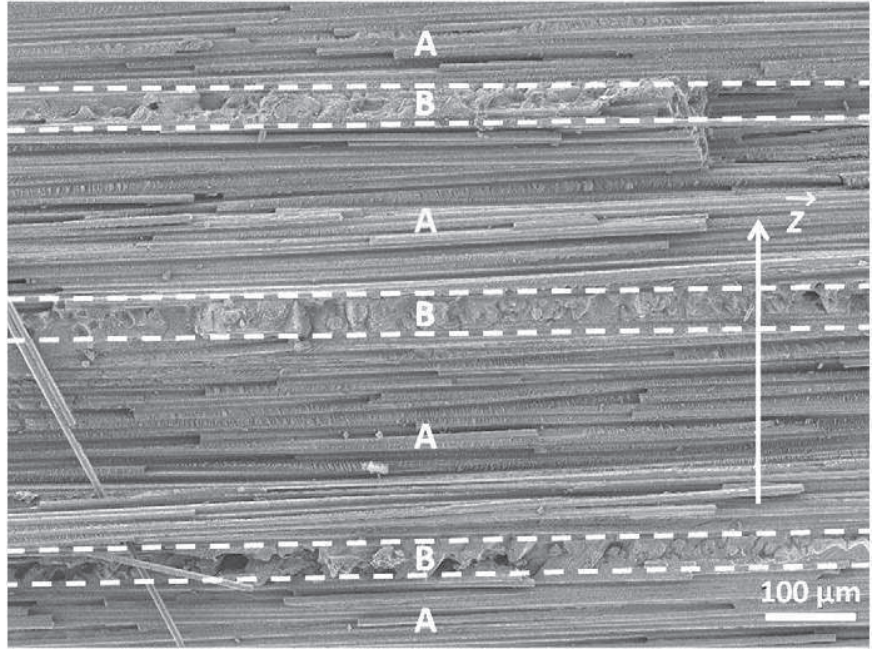

Fig. 1. SEM image of the cryo-fractured surface of a T700GC/M21 epoxy carbon fiber unidirectional composite. Excess resin interlayers (B) between prepreg UD carbon fiber layers (A).

Fig. 2 shows the dynamic conductivity response of each constituent part of the composite structure. The bulk conductivity of the M21 epoxy reference is frequency dependent. It is consistent with the Jonscher's universal dielectric response expected for an insulating material. The real part of the complex conductivity value is equal to $10^{-13} \mathrm{~S} \cdot \mathrm{m}^{-1}$ at $10^{-2} \mathrm{~Hz}$. As it is usual in a percolation network, all other morphologies are not frequency dependent. The evolution of the conductivity value is associated with the quality of the percolation pathway.

Table 1 reports the value of $\sigma_{\mathrm{dc}}$ of the conductivity in the $\mathrm{z}$ direction.

\section{Discussion}

The $\sigma_{\mathrm{dc}}$ measurement of the reference M21 carbon fiber composite confirms the poor conductivity value of the laminate in the transverse direction. The conduction phenomenon is due to a percolation cluster across the carbon plies. Conduction between fiber plies could be achieved by few contacts of fibers which connect successive unidirectional ply. The conduction pathway was localized and fragile. The reproducibility of the conductivity level was dependent upon: the applied pressure on laminate during the polymerization [1] and the ability of isolated carbon fiber to cross the epoxy rich layer. The addition of CNTs was able to fix this phenomenon. In the case of M21 filled with CNTs the percolative cluster is infinite and the conductivity value corresponds to carbon black particles conductive composites

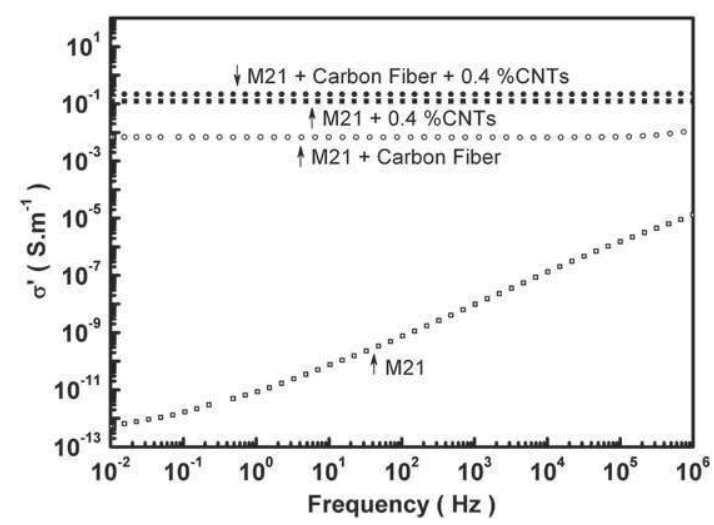

Fig. 2. Frequency dependence of the real part $\sigma^{\prime}$ of the complex conductivity for M21 epoxy resin $(\square)$, carbon fiber composite (O), M21 epoxy filled with CNTs ( $(\square)$ and carbon fiber composites with M21 epoxy resin filled in CNTs $(\bullet)$ 
Table 1

M21 reference, nanocomposite and layered composite transverse conductivity measurements.

\begin{tabular}{cllll}
\hline Morphology & M21 & CF + M21 & M21 + DWCNTs & M21 + CF + DWCNTs \\
\hline $\begin{array}{c}\text { Conductivity } \\
\left(\mathrm{S} \cdot \mathrm{m}^{-1}\right)\end{array}$ & $5 \times 10^{-13}$ & $7.1 \times 10^{-3}$ & $1.23 \times 10^{-1}$ & $2.17 \times 10^{-1}$ \\
\hline
\end{tabular}

largely filled above the percolation threshold in homogeneous dispersed systems. In carbon fiber M21 laminates filled with CNTs, the conductive pathway could be constituted by the continuity between conductive cluster of CNTs and carbon fibers.

The conductivity value means that $0.4 \mathrm{wt} . \%$ of CNTs is sufficient to achieve the electrical percolation. The level of conductivity is consistent with values obtain with CNTs dispersed in epoxy $[8,10,22]$. Fig. 3 shows the dispersion of CNTs in M21 polymer matrix. We observe thin dispersed bundles of CNTs of $15 \mathrm{~nm}$ in diameter. This value indicates a number of CNTs less than 10 CNTs by bundles. At the end of the bundle we note an individualization of CNTs.

The dispersion of CNTs needs to be observed in carbon fiber laminates. Fig. 4 focuses on the carbon fiber inter-ply area more rich in epoxy. The SEM picture shows thin bundles of DWCNTs individually dispersed in the M21 matrix. The good dispersion of CNTs observed in epoxy M21 was kept in the laminate final structure.

The conductivity in final carbon fiber composites filled with CNTs was increased 30 -fold. The final composites reach the electrical conductivity value of carbon filled composite above the percolation value. CNTs play the role of conductive cluster in the M21 layer to electrically link the carbon fiber plies. Fig. 5 shows the epoxy layer on a carbon fiber. A focus on the direct interface exhibits individual CNTs dispersed in the matrix in direct contact with the carbon fiber. The M21 epoxy matrix filled with CNTs has impregnated the UD carbon fiber layer. The final conductivity value of composite and the SEM observations confirm a good dispersion of CNTs in the matrix responsible of the homogenization of the conductivity through the final composite structure. Our transversal conductivity $\left(2.17 \times 10^{-1} \mathrm{~S} \cdot \mathrm{m}^{-1}\right)$ is comparable to the case of CNTs deposited on CF by electrophoresis [18] $\left(8.5 \times 10^{-2} \mathrm{~S} \cdot \mathrm{m}^{-1}\right)$.

\section{Conclusion}

These results illustrate the reasons for the poor transverse conductivity of aeronautical carbon fiber M21 epoxy composites structures. A $35 \mu \mathrm{m}$ layer of epoxy with a low concentration of carbon fiber was

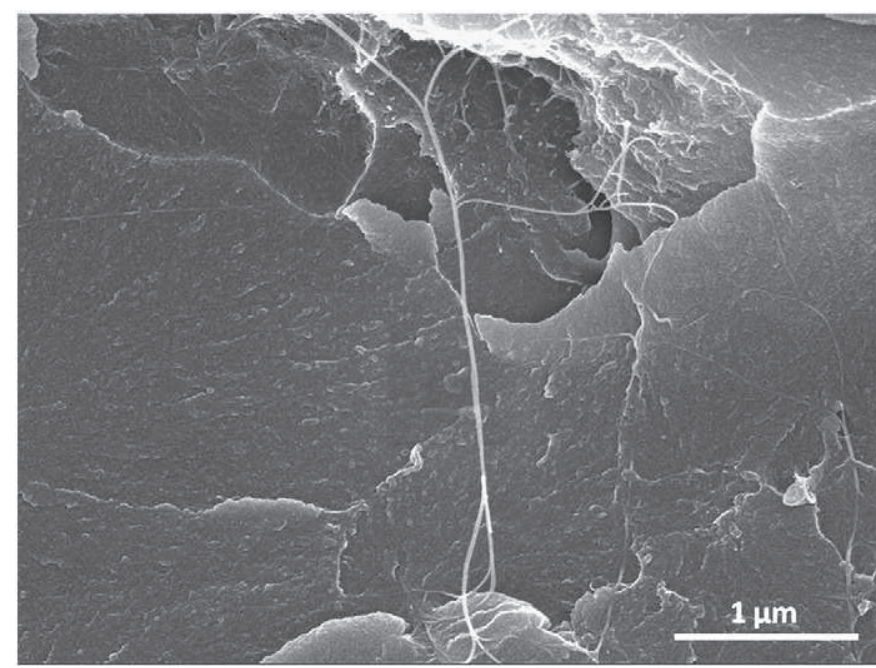

Fig. 3. SEM image of CNTs/M21 epoxy nanocomposites for 0.4 wt.\% of CNTs.

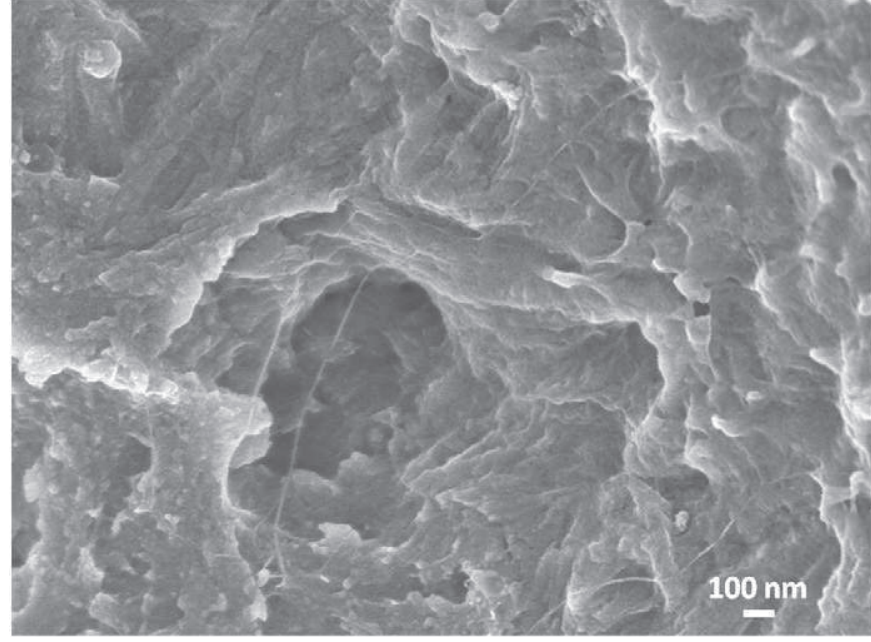

Fig. 4. SEM picture of the interply epoxy rich zone for carbon fiber composites with M21 epoxy filled for 0.4 wt.\% of CNTs.

formed at the interface of carbon fiber plies. The epoxy layer is not thin enough to permit a large carbon fiber interply contact necessary to obtain the highest conductivity value of carbon loaded conductive composites. The addition of CNTs causes a large increase in the conductivity of the epoxy matrix M21. This work confirms the use of palmitic acid like dispersing agent in epoxy systems [22]. This dispersion process enables the realization of the percolation threshold at lower rates and achieves a level of conductivity around $10^{-1} \mathrm{~S} \cdot \mathrm{m}^{-1}$ for 0.4 wt.\% by weight of CNTs in pure M21 epoxy matrix. This level of transverse bulk conductivity was kept in final assembled laminate for a loading corresponding to $0.12 \mathrm{wt}$.\% with regard to the carbon fiber laminar composite. This study demonstrates that the introduction of a very small fraction of CNTs in the epoxy matrix is sufficient to induce a 30-fold improvement and a homogenization of the transverse conductivity of carbon reinforced fiber polymer composite. The process is easily adaptable for the new generation of aeronautical prepregs and permits the charge transport between each ply of structural carbon fiber composites.

\section{Acknowledgments}

The authors thank the financial support from DGCIS and Région Midi-Pyrénées through the NACOMAT program. Marion Technologies

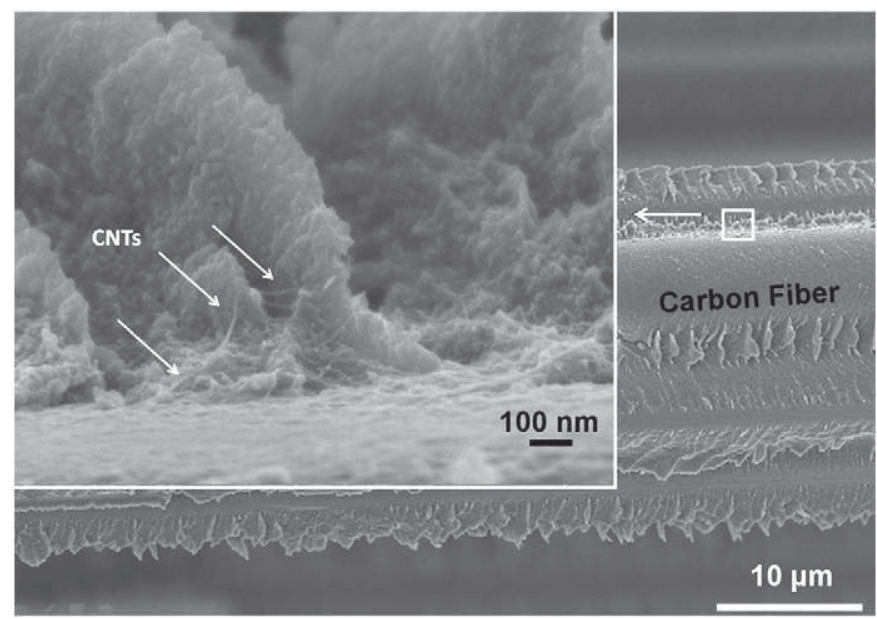

Fig. 5. SEM image of carbon fiber surface of carbon fiber reinforced epoxy filled with CNTs composite. The selected area shows the direct contact between CNTs dispersed in M21 epoxy matrix and carbon fiber embedded in this matrix. 
is acknowledged for the supply of DWCNTs. Isabelle Blanc of the Hexcel Composites company, France is acknowledged for the supply of M21 epoxy resin and for the CFRC manufacturing. Jean-Michel Bergerat from AIRBUS S.A.S. is also acknowledged for the helpful discussion.

\section{References}

[1] S. Wang, D.D.L. Chung, Compos. Interfaces 6 (1999) 497.

[2] A.I. Medalia, Rubber Chem. Technol. 59 (1986) 432

[3] H. Tang, X. Chen, A. Tang, Y. Luo, J. Appl. Polym. Sci. 59 (1996) 383.

[4] F. Lux, J. Mater. Sci. 28 (1993) 285.

[5] F.J. Baltá-Calleja, R.K. Bayer, T.A. Ezquerra, J. Mater. Sci. 23 (1988) 1411

[6] V.M. Drakonakis, C.N. Velisaris, J.C. Seferis, C.C. Doumanidis, B.L. Wardle, G.C Papanicolaou, Polym. Compos. 31 (1965)

7] S. lijima, Nature (London) 354 (1991) 56.

[8] W. Bauhofer, J.Z. Kovacs, Compos. Sci. Technol. 69 (2009) 1486

[9] S.C. Schulz, G. Faiella, S.T. Buschhorn, L.A.S.A. Prado, M. Giordano, K. Schulte, W. Bauhofer, Eur. Polym J. 47 (2011) 2069

[10] S. Barrau, P. Demont, A. Peigney, C. Laurent, C. Lacabanne, Macromolecules 36 (2003) 5187
[11] W. Bauhofer, S.C. Schulz, A.E. Eken, T. Skipa, D. Lellinger, I. Alig, E.J. Tozzi, DJ Klingenberg, Polymer 51 (2010) 5027

[12] M. Chapartegui, N. Markaide, S. Florez, C. Elizetxea, M. Fernandez, A. Santamaría Compos. Sci. Technol. 70 (2010) 879.

[13] R.F. Gibson, Compos. Struct. 92 (2010) 2793.

[14] F.H. Gojny, M.H.G. Wichmann, B. Fiedler, W. Bauhofer, K. Schulte, Composites Part A 36 (2005) 1525

[15] E.J. Garcia, B.L. Wardle, A.J. Hart, N. Yamamoto, Compos. Sci. Technol. 68 (2008) 2034

[16] G. Morales, M.I. Barrena, J.M. Gómez De Salazara, C. Merino, D. Rodríguez, Compos. Struct. 92 (2010) 1416.

[17] E.J. Garcia, B.L. Wardle, A.J. Hart, Composites Part A 39 (2008) 1065.

[18] E. Bekyarova, E.T. Thostenson, A. Yu, H. Kim, J. Gao, J. Tang, H.T. Hahn, T.W. Chou, M.E. Itkis, R.C. Haddon, Langmuir 23 (2002) 3970.

[19] L. Laffont, M. Monthioux, V. Serin, Carbon 40 (2002) 767.

[20] E. Flahaut, A. Peigney, C. Laurent, A. Rousset, J. Mater. Chem. 10 (2000) 249.

[21] T.W. Ebbesen, H.J. Lezec, H. Hiura, J.W. Bennett, H.F. Ghaemi, T. Thio, Nature 382 (1996) 54.

[22] S. Barrau, P. Demont, E. Perez, A. Peigney, C. Laurent, C. Lacabanne, Macromolecules 36 (2003) 9678

[23] F. Kremer, A. Schönhals. Springer, Berlin (2002). 